\title{
PENGUATAN PARTISIPASI PETANI MELALUI PENYULUHAN PERTANIAN DI KECAMATAN RASANAE TIMUR KOTA BIMA
}

\author{
Puji Muniarty ${ }^{1}$, Wulandari ${ }^{2}$, Aliah Pratiwi ${ }^{3}$, \\ Firmansyah Kusumayadi $^{4}$, Intisari Haryanti ${ }^{5}$
}

\author{
Sekolah Tinggi Ilmu Ekonomi (STIE) Bima, NTB, Indonesia \\ Email:puji.stiebima@gmail.com
}

\begin{abstract}
Abstrak
Penyuluh pertanian mendampingi petani dalam berusaha tani agar menjadi tahu, mau dan mampu mengelola usahanya sehingga menjadi usaha tani yang efisien dengan memanfaatkan sumberdaya alam yang ada, mampu meningkatkan produktivitas, dan pendapatan serta kesejahteraannya. Penguatan partisipasi menitikberatkan pada perubahan perilaku petani akan nampak pada peningkatan kompetensi pengelolaan usaha tani dan meningkatnya partisipasi petani mengikuti penyuluhan. Penyuluhan sistem LAKU (Latihan dan Kunjungan) yang berpola dyadic memadukan kepentingan top down dan bottom up dengan pendekatan komunikasi interpersonal maupun kelompok. Pemilihan lokasi Pengabdian Kepada Masyarakat (PKM) ini dilakukan secara sengaja (purposive) sesuai dengan sentra pengembangan usaha tani di Kota Bima. Proses pengabdian kepada masyarakat terkait partisipasi diukur melalui; kualitas dan kuantitas keterlibatan/partisipasi masyarakat mulai dari kegiatan kajian atau analisis masalah, perencanaan program, pelaksanakan program, serta keterlibatan dalam evaluasi secara berkelanjutan. Partisipasi tinggi menyebabkan pelaksanaan penyuluhan berorientasi kepada kebutuhan petani yang memperhatikan keberagaman lokal dan sumberdaya yang dimiliki. Pelaksanaan program dengan tingkat partisipasi tinggi juga dapat meningkatkan efisiensi dan pemanfaatan biaya.
\end{abstract}

Kata Kunci: Partisipasi, Penyuluhan Pertanian.

\section{Abstract}

Agricultural instructors assist farmers in farming so that they know, want and are able to manage their business so that it becomes an efficient farming business by utilizing existing natural resources, able to increase productivity, and their income and welfare. Strengthening participation by focusing on changes in farmer behavior will be seen in increasing the competence of farm management and increasing farmer participation in attending counseling. The dyadic pattern of LAKU (Exercises and Visits) counseling combines top down and bottom up interests with interpersonal and group communication approaches. The location selection for Community Service (PKM) was carried out purposively in accordance with the farming business development center in Bima City. The process of community service related participation is measured through; the quality and quantity of community involvement / participation starting from the study or problem analysis, program planning, program implementation, and involvement in ongoing evaluation. High participation has led to the implementation of extension activities oriented to the needs of farmers who pay attention to local diversity and available resources. Implementing programs with a high level of participation can also increase efficiency and increase cost utilization.

Keywords: Participation, Agricultural Extension. 


\section{PENDAHULUAN}

Sesuai kebijakan pembangunan daerah Kota Bima yang dijabarkan pada Programa Rasanae Timur tahun 2020, maka kebijakan penyuluhan pertanian bertujuan meningkatkan pendapatan serta kesejahteraan petani dan keluarganya beserta masyarakat pelaku agribisnis melalui peningkatan produktivitas dan efisiensi usaha dengan cara meningkatkan kemampuan dan pemberdayaan petani. Pemberdayaan sebagai kegiatan untuk memperkuat keberdayaan kelompok lemah dalam masyarakat agar berdaya mempunyai pengetahuan dan kemampuan dalam memenuhi kebutuhan hidupnya baik yang bersifat fisik, ekonomi maupun sosial seperti mempunyai mata pencaharian, berpartisipasi dalam kegiatan sosial dan mandiri (Fitria, 2014). Kenyataan di lapangan tidak semua petani aktif berpartisipasi dalam kegiatan penyuluhan. Hal ini terlihat pada Laporan penyuluhan tingkat WKPP menunjukkan jumlah petani yang aktif dalam kegiatan anjangsana kelompok tani tidak sesuai dengan rencana kegiatan penyuluhan pertanian yaitu hanya 30\% dari anggota.

Rendahnya partisipasi sesuai programa penyuluhan BPP Rasanae Timur terlihat bahwa keragaan penerapan teknologi produksi yang diterapkan oleh petani dari paket teknologi yang dianjurkan baru mencapai $66 \%$ hal ini menyebabkan tingkat produktivitas usaha tani masih belum memenuhi standar yaitu 80\% PSK petani menerapkan teknologi budidaya padi di Kecamatan Rasanae Timur khususnya di Kelurahan Kodo dan sekitarnya. Selain itu, penerapan teknologi padi yang belum optimal dan kurang berfungsinya kelembagaan tani sehingga belum melaksanakan fungsinya serta tingginya ketergantungan petani terhadap pupuk anorganik membutuhkan penyuluhan dalam mendampingi petani.

Undang-Undang Nomor 16 tahun 2006 tentang Sistem Penyuluhan, Pertanian, Perikanan, dan Kehutanan yang menghendaki adanya partisipasi masyarakat dan kearifan lokal dari pelaksanaan otonomi daerah. Ikbal (2015) menyatakan pelaksanaan penyuluhan akan berhasil dengan baik, jika penyuluh mampu melibatkan masyarakat dalam setiap perencanaan dan pelaksanaan program penyuluhan. Hal ini bermanfaat untuk keberhasilan dan keberlangsungan penyelenggaraan program penyuluhan. Penyuluh pertanian sebagai agen perubahan tentunya mempunyai tugas dan tanggung jawab yang besar dalam mengimplementasikan program penyuluhan secara efektif dan efisien dengan memperhatikan kondisi lingkungan pertanian dan kondisi lingkungan bisnis pertanian yang akan berdampak pada peningkatan pendapatan petani secara berkelanjutan sesuai dengan kearifan lokal dan potensi daerah.

Keberdayaan petani berkaitan erat dengan kinerja penyuluhan. Kinerja penyuluh pertanian yang baik, akan berdampak pada perubahan perilaku petani dalam berusaha tani. Lantas jika dikaitkan dengan sistem kerja Latihan dan Kunjungan (LAKU), jelas digariskan bahwa PPL setiap minggunya adalah, 4 hari untuk melakukan kunjungan ke kelompok tani (poktan) dan 1 hari guna keperluan latihan dan menyelesaikan administrasi. Tetapi kenyataannya, sistem LAKU ini masih sulit diterapkan mengingat beberapa alasan. Idealnya, satu orang PPL melayani $300 \mathrm{KK}$ di masing-masing desa 
(Sastraatmadja, 1993), tetapi karena kekurangan personil tenaga PPL harus melayani lebih besar dari 2000 KK dalam satu desa. Jika semula penyuluhan ditekankan pada bimbingan kepada petani dalam berusaha tani yang lebih baik, berubah menjadi tekanan pada alih teknologi yakni mengusahakan agar petani mampu berpartisipasi pada kegiatan penyuluhan melalui teknologi informasi yang telah berkembang.

\section{METODE}

Pemilihan lokasi Pengabdian Kepada Masyarakat (PKM) ini dilakukan secara sengaja (purposive), dengan pertimbangan bahwa Kecamatan Rasanae Timur merupakan sentra pembangunan pertanian di Kota Bima dengan luas areal sawah irigasi 1112 ha dari total 2.384 ha sawah di Kota Bima. Data pada PKM ini terdiri dari; pelaksanaan desiminasi/penyebaran materi penyuluhan pertanian sesuai kebutuhan petani dan pelaksanaan penerapan metode penyuluhan pertanian di wilayah binaan, dukungan kebijakan penyuluhan Dinas Pertanian Kota Bima; pengetahuan, sikap dan keterampilan petani padi, partisipasi petani, dan kapasitas petani kaitannya dengan pelaksanaan penyuluhan serta potensi dan hambatan pelaksanaan penyuluhan.

Penguatan mengenai partisipasi petani penerima pemberdayaan terdiri dari; keterlibatan perencanaan untuk langkah-langkah pelaksanaan usaha tani padi, keterlibatan pelaksanaan usaha tani padi sesuai anjuran, keterlibatan pemanfaatan sarana prasarana usaha tani padi dan keterlibatan evaluasi pelaksanaan penyuluhan usaha tani padi.

\section{HASIL DAN PEMBAHASAN}

Salah satu syarat dan faktor pelancar pembangunan pertanian adalah kebijakan pemerintah untuk pembangunan pertanian dan penjabarannya oleh aparat pemerintah di tingkat regional dan lokal, serta langkah-langkah pelaksanaannya yang telah dimusyawarahkan oleh warga masyarakat setempat. Oleh karena itu, Yanto (2016) menyatakan penyelenggaraan penyuluhan pertanian di suatu daerah harus mengacu pada kebijakan pemerintah yang terkait dengan pembangunan pertanian yang ada di daerah tersebut. Penyuluh sebagai ujung tombak yang langsung berhubungan dengan pelaku utama melakukan pengkajian rencana kerja penyuluhan sesuai dengan kondisi dan kebutuhan pertanian di WKPP masing-masing. Hal ini sejalan dengan hasil penelitian Sucihatiningsih (2010) menyatakan bahwa proses penyelenggaraan penyuluhan pertanian dapat berjalan dengan baik apabila didukung dengan kelembagaan penyuluhan, materi penyuluhan dan pengembangan masyarakat petani melalui kelompoktani.

Pendekatan secara perorangan dilakukan oleh penyuluh melalui pendampingan kegiatan demplot kepada petani pelaksana. Namun pemberdayaan petani dan keluarganya melalui penyelenggaraan penyuluhan pertanian tidak mungkin dilaksanakan dengan pendekatan individual, karena jumlah dan sebaran petani sangat besar dan luas serta terbatasnya sumberdaya penyuluhan. Dengan kondisi demikian, penyuluhan pertanian harus dilakukan melalui pendekatan kelompok. Pendekatan ini 
akan mendorong petani membentuk kelembagaan tani yang kuat agar dapat membangun sinergi antar petani, baik dalam proses belajar dan kerjasama maupun sebagai unit produksi yang merupakan bagian dari usaha taninya.

Partisipasi merupakan suatu proses dimana warga atau petani padi punya insiatif ikut serta atau aktif terlibat dalam kegiatan-kegiatan penyuluhan di WKBPP Rasanae Timur. Untuk meningkatkan adopsi teknologi salah satunya adalah melalui peningkatan partisipasi petani padi dalam penyuluhan. Partisipasi tinggi menyebabkan pelaksanaan penyuluhan berorientasi kepada kebutuhan petani yang memperhatikan keberagaman lokal dan sumberdaya yang dimiliki. Pelaksanaan program dengan tingkat partisipasi tinggi juga dapat meningkatkan efisiensi dan pemanfaatan biaya.

Peranan yang dapat dimainkan oleh penyuluh di WKBPP Rasanae Timur dan petani atau para wakilnya dalam merencanakan program penyuluhan, salah satunya ikut terlibat dalam perencanaan Rencana Definitif Kebutuhan Kelompok (RDKK). Penyuluh menawarkan pilihan varietas benih padi dan anjuran pemupukan, tergantung pada hak-hak yang dimiliki masing-masing kelompok untuk mengambil keputusan, salah satu pertimbangan mengenai hak ini adalah dampaknya pada motivasi penyuluh dan petani untuk mencapai tujuan program. Makin kecil skala usaha petani, maka petani semakin takut dengan risiko karena kegagalan panen akan berpengaruh pada masalah ketahanan pangan (Suci, 2011).
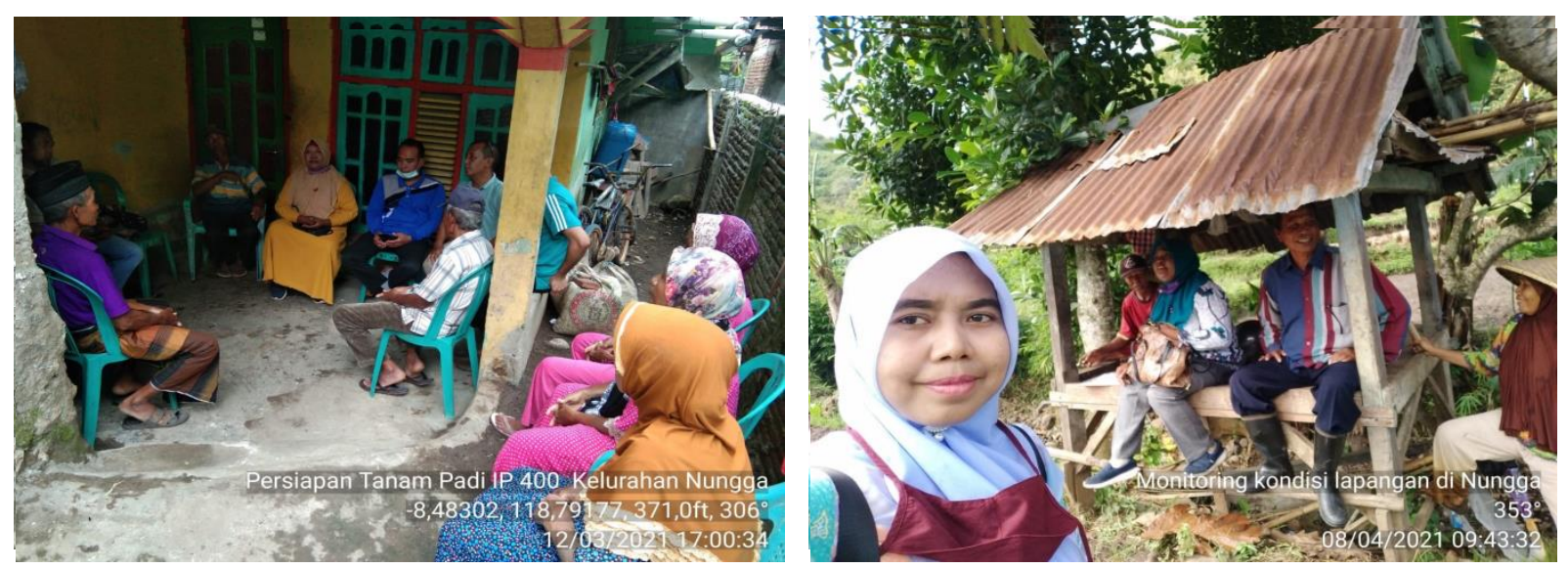

Gambar 1. Pendampingan Penyuluh Terkait Program dan Kebijakan Stakeholder

Salah satu evaluasi yang dibahas bersama oleh petani dan penyuluh bersama stakeholders yaitu mengenai ketepatan program dengan musim tanam padi di tiap WKPP. Penyuluh menganjurkan penggunaan pupuk sesuai rekomendasi sedangkan ketersediaan pupuk tidak memadai di pengecer. Ada beberapa alasan mengapa petani di anjurkan berpartisipasi dalam keputusan-keputusan yang berkaitan dengan program penyuluhan, yaitu (a) Petani memiliki informasi yang sangat penting untuk merencanakan program yang berhasil, termasuk tujuan, situasi, pengetahuan serta pengalaman, (b) Petani akan lebih termotivasi untuk berkerjasama dalam program penyuluhan jika ikut bertanggung jawab didalamnya, (c) Petani yang demokratis secara 
umum menerima bahwa mereka yang terlebih berhak berpartisipasi dalam keputusan mengenai tujuan yang ingin mereka capai.

Diskusi-diskusi yang membahas perihal keberhasilan dan kegagalan dari kegiatan mengolah tanah sampai panen antara penyuluh dan petani jarang dilakukan di WKBPP Rasane Timur. Besar kemungkinan bahwa setiap program kegiatan yang sudah digariskan dari atas, terutama untuk kelayakan teknologi tanaman pangan, dievaluasi di tingkat atas saja. Layak atau tidaknya teknologi tanaman pangan tersebut, tidak perlu didiskusikan dengan petani kecuali indikator-indikator fisik dan ekonomi yang dapat dicari melalui metode survei. Ringkasnya, dalam rangka evaluasi layak atau tidaknya suatu teknologi pola tanam (tanaman pangan), petani tidak diberi kesempatan cukup untuk berpartisipasi. Sesuai pernyataan Firmansyah (2017), pemimpin kelompok tani disini memiliki peran yang sangat penting didalam kelompok yaitu sebagai koordinator kelompok, dimana mereka yang menjelaskan atau menunujukan hubungan antara berbagai pendapat serta saran, sementara disisi lain setiap anggota berhak memainkan lebih dari satu peran dalam partisipasi kelompok. Dilain hal pemimpin kelompok bisa menjadi suatu penggerak didalam bertindak atau mengambil keputusan dan berusaha untuk merangsang suatu kelompok agar tetap melakukan suatu kegiatan yang sudah ditentukan sebelumnya. Petani juga aktif dalam percontohan kegiatan penanaman jajar legowo. Penyuluh di Kecamatan Rasanae Timur selain memberikan materi cara tanam jajar legowo, juga langsung praktek cara tanam padi dengan sistem legowo 4:1. Setelah panen, penyuluh masih tetap aktif mendampingi sampai perhitungan produktivitas komoditi.
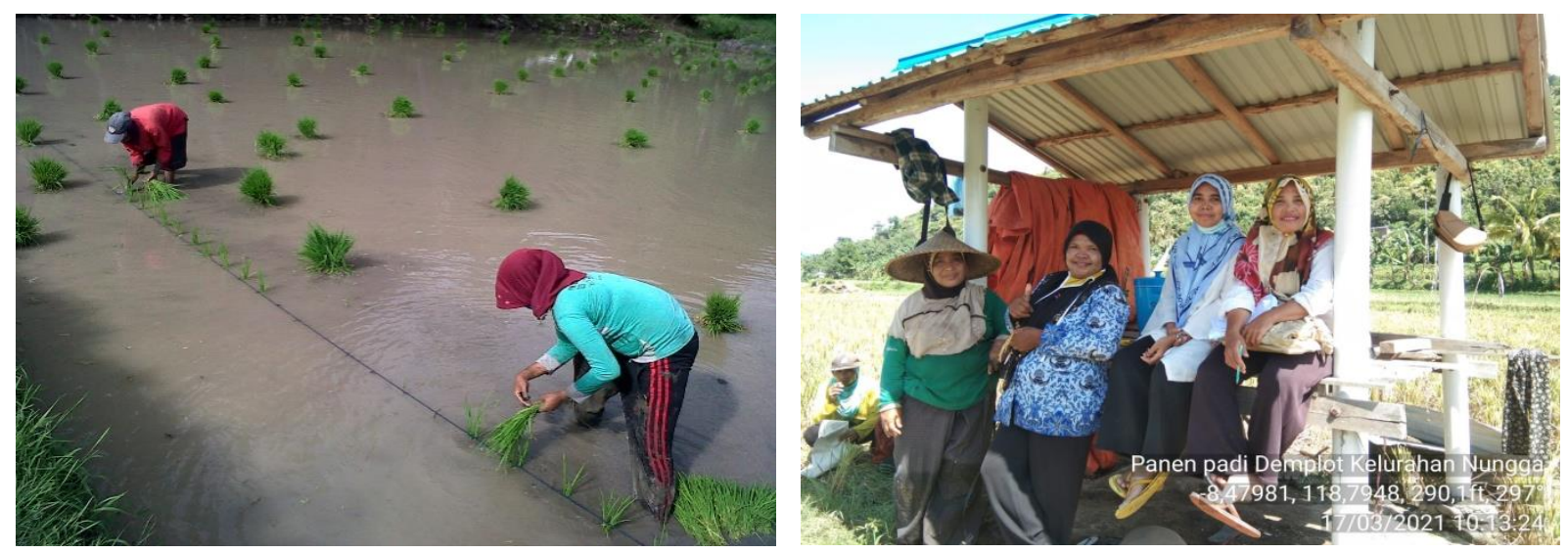

Gambar 2. Kegiatan Pendampingan Penyuluh Pertanian Terkait Partisipasi Petani Dalam Penanaman Sampai Panen

Meningkatnya suatu partisipasi kelompok akan memunculkan peningkatan kedinamisan kelompok. Kedinamisan kelompok inilah yang akan membuat peluang sebesar-besarnya kepada anggota kelompok untuk bekerjasama dan berpartisipasi dalam memajukan suatu kelompok yang membuat tujuan yang dibuat tercapai. Kelompok tani yang dinamis ditandai dengan adanya interaksi didalam kelompok baik itu keluar maupun kedalam guna mencapai tujuan kelompok. 


\section{KESIMPULAN}

Peran penyuluhan pertanian dalam penguatan partisipasi petani yaitu mengupayakan transfer inovasi teknologi pertanian kepada masyarakat sasaran dalam bentuk pendidikan non formal sebagai upaya meningkatkan kualitas sumber daya manusia sesuai dengan kearifan lokal di lingkungan petani. Peran penyuluhan pertanian didasarkan pada tugas pokok dan fungsi penyuluh dalam mengimplementasikan program penyuluhan yang disusun secara bersama-sama dengan pelaku utama dan pelaku usaha. Petani dan penyuluh akan bersinergi secara berkesinambungan untuk menumbuh kembangkan potensi sumber daya lokal sebagai usaha meningkatkan produksi usaha tani. Bagian ini memberikan kesimpulan tentang tingkat pencapaian pengabdian kepada masyarakat, dampak dan manfaat pengabdian kepada masyarakat, serta memberikan rekomendasi untuk kegiatan pengabdian kepada masyarakat lebih lanjut.

\section{REFERENSI}

Firmansyah, H. (2017). Strategi Komunikasi Dalam Penguatan Kapasitas Kelembagaan Pada Pengelolaan Lahan Gambut Melalui Peningkatan Sumberdaya Manusia Di Sektor Pertanian Kalimantan Selatan. Meta Communication; Journal of Communication Studies, 2(1), 119-131.

Fitria, S., R. Laily, H. Ribawanto, \& F. Nurani. (2014). Pemberdayaan Petani Dalam Meningkatkan Ketahanan Pangan (Studi Di Desa Betet, Kecamatan Ngronggot, Kabupaten Nganjuk). Jurnal Administrasi Publik (JAP), 2(1), 147-153.

Ikbal, M. (2015). Penyuluhan dan Pemberdayaan Petani Indonesia. Gorontalo: Ideas Publishing.

Sastraatmadja, E. (1993). Penyuluhan Pertanian: Falsafah, Masalah dan Strategi. Bandung: Alumni.

Suci, K. (2011). Faktor-Faktor Yang Mempengaruhi Kinerja Usahatani Petani Sebagai Representasi Strategi Penyuluhan Pertanian Berkelanjutan di Lahan Marjinal. Jurnal Agro Ekonomi, 9(1), 1-24.

Sucihatiningsih. (2010). Model Penguatan Kapasitas Kelembagaan Penyuluh Pertanian Dalam Meningkatkan Kinerja Usahatani Studi Empiris di Provinsi Jawa Tengah. Jurnal Ekonomi Pembangunan, 2(1), 13-29.

Yanto. (2016). Implementasi Kebijakan Penyuluhan Pertanian Pada Penyuluh Pertanian Lapangan (PPL) di Badan Pelaksanaan Penyuluhan Pertanian, Perikanan dan Kehutanan (BP4K) Kabupaten Karawang. Jurnal Implementasi Kebijakan Penyuluhan Pertanian, 1-16.

Undang Undang Republik Indonesia Nomor 16 Tahun 2006 tentang Sistem Penyuluhan Pertanian, Perikanan, Dan Kehutanan. 